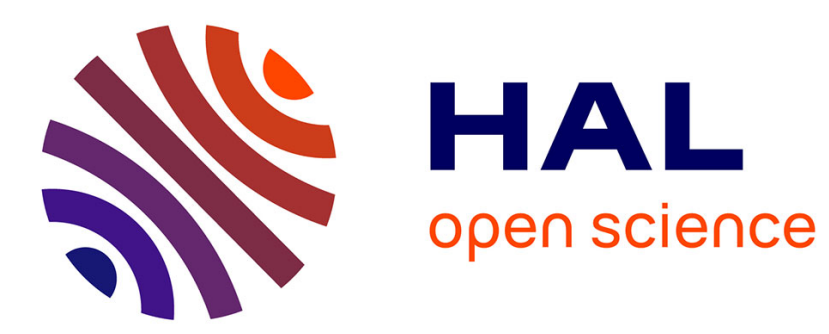

\title{
Internal Friction Peak in Cold-Worked "Pure" Aluminum and Aluminum Alloys
}

\author{
X. Guan, H. Numakura, M. Koiwa
}

\section{To cite this version:}

X. Guan, H. Numakura, M. Koiwa. Internal Friction Peak in Cold-Worked "Pure" Aluminum and Aluminum Alloys. Journal de Physique IV Proceedings, 1996, 06 (C8), pp.C8-219-C8-222. 10.1051/jp4:1996846 . jpa-00254654

\section{HAL Id: jpa-00254654 https://hal.science/jpa-00254654}

Submitted on 1 Jan 1996

HAL is a multi-disciplinary open access archive for the deposit and dissemination of scientific research documents, whether they are published or not. The documents may come from teaching and research institutions in France or abroad, or from public or private research centers.
L'archive ouverte pluridisciplinaire HAL, est destinée au dépôt et à la diffusion de documents scientifiques de niveau recherche, publiés ou non, émanant des établissements d'enseignement et de recherche français ou étrangers, des laboratoires publics ou privés. 


\title{
Internal Friction Peak in Cold-Worked "Pure" Aluminum and Aluminum Alloys
}

\author{
X.S. Guan, H. Numakura* and M. Koiwa
}

Department of Materials Science and Engineering, Kyoto University, Kyoto 606-01, Japan

* LMPM-ENSMA, Site du Futuroscope, Chasseneuil du Poitou, BP. 109, 86960 Futuroscope cedex, France

\begin{abstract}
Low frequency internal friction measurements have been made on "pure" aluminum and dilute aluminum alloys in heavily cold-worked states. A relaxation peak is observed at about $200 \mathrm{~K}$ (for $1 \mathrm{~Hz}$ ) even in specimens of nominally $4 \mathrm{~N}$ or higher purity. This peak is considered to be the same as those previously reported by several researchers for dilute aluminum alloys of $\mathrm{Cu}, \mathrm{Mg}$ or $\mathrm{Ga}$. Among various elements so far examined ( $\mathrm{Cu}, \mathrm{Si}, \mathrm{Fe}, \mathrm{Ge}, \mathrm{Mg}$ ), Si has a dominant effect. The anomalous features of the peak, i.e. high activation energy and small preexponential factor for the relaxation time can be understood in terms of a model in which the anelastic elements exhibit strong interaction .
\end{abstract}

\section{INTRODUCTION}

Internal friction associated with dislocations in metals has long been studied extensively. The relaxation peaks appearing at low temperatures in cold-worked metals are usually called the Bordoni peak. It is now generally accepted that the peak is due to the intrinsic motion of dislocations over the Peierls barrier. At temperatures higher than that of the Bordoni peak, several peaks have been observed. This group of peaks has been referred to as the Hasiguti peaks. Extensive investigations have been performed for $\mathrm{Au}$ and $\mathrm{Cu}$, and the peak is considered to be due to dislocations combined with physical point defects such as vacancies and interstitial atoms introduced by cold working [1].

One might then expect the appearance of relaxation peaks of dislocations combined with chemical point defects, i.e., solute atoms. The Snoek-Köster peaks in b.c.c. metals containing interstitial impurity atoms are considered to be of such nature [1]; extensive studies have been made for $\mathrm{Fe}-\mathrm{N}$ and $\mathrm{Fe}-\mathrm{H}$ alloys. In f.c.c. metals, several researchers have observed relaxation peaks in copper alloys: $\mathrm{Cu}-\mathrm{Ag}[2,3], \mathrm{Cu}-\mathrm{Al}$ $[4,5,6], \mathrm{Cu}-\mathrm{Zn}[6]$ and in aluminum alloys: $\mathrm{Al}-\mathrm{Cd}, \mathrm{Al}-\mathrm{Sn}[7], \mathrm{Al}-\mathrm{Cu}[8], \mathrm{Al}-\mathrm{Ga}[9], \mathrm{Al}-\mathrm{Mg}[10,11]$. In contrast to the case of b.c.c. metals, our understanding of the nature of the peaks is far from complete. One important difference exists in the peak characteristics; in b.c.c. metals the peak appears at temperatures where the solute atoms are mobile, e.g., $480 \mathrm{~K}$ at $1 \mathrm{~Hz}$ for $\mathrm{Fe}-\mathrm{N}$, while in f.c.c. metals the peaks appear around $200 \mathrm{~K}$ where the mobility of substitutional solute atoms must be negligibly low.

In the course of an internal friction study on a series of Al-Mg alloys [12], we noticed the presence of a relaxation peak at about $200 \mathrm{~K}$ even in a reference specimen of pure aluminum of high purity, when measured after heavy cold working. It is suspected if the peak is related to some trace impurities. In this paper we report the result of low frequency internal friction measurements on pure aluminum and dilute aluminum alloys.

\section{EXPERIMENTAL PROCEDURES}

Three kinds of "pure" aluminium ingots were supplied by Sumitomo Chemical Co. Ltd.; 99.95, 99.992 and 99.9996 wt\%. Dilute alloys were prepared from the ingot of the highest purity and the respective solute element: $\mathrm{Cu}, \mathrm{Fe}, \mathrm{Si}$ and $\mathrm{Ge}$ of comparable purity; the alloy specimens were subjected to homogenization anneals at $560^{\circ} \mathrm{C}$ for 4 days. Wire specimens of $1.2 \mathrm{~mm}$ in diameter were prepared from the pieces cut from the ingots through groove rolling and drawing. For alloy specimens, intermediate 
annealing was made at the diameter of $2 \mathrm{~mm}$ for $1 \mathrm{~h}$ at $350^{\circ} \mathrm{C}$. The as-drawn specimens were immediately mounted in an inverted torsion pendulum apparatus [13]. Internal friction was measured on heating over the temperature range from $80 \mathrm{~K}$ to $640 \mathrm{~K}$ at a heating rate of $1 \mathrm{~K} \mathrm{~min}^{-1}$. The vibrational frequency and the strain amplitude in the surface shear strain are typically $1 \mathrm{~Hz}$ and $10^{-6}$.

\section{RESULTS}

Figure 1 shows the internal friction vs. temperature curves for as-drawn "pure" aluminum specimens of different purity. For two specimens of lower purity, 99.95 and $99.992 \mathrm{wt} . \%$, peaks are observed around $200 \mathrm{~K}$, but not in the specimen of highest purity of $99.9996 \mathrm{wt} \%$, the commercial name of which is Supral. All the other "pure Al" specimens measured in this experiment exhibited peaks at the same temperature, although the nominal purity was claimed to be 99.99 or $99.999 \mathrm{wt} . \%$. Thus, it is suspected that some trace elements in $\mathrm{Al}$ are responsible for the appearance of the peak.

In order to identify the impurity responsible for the peak, we have made measurements on dilute alloys as shown in Fig.2. In commercial aluminum, the major impurities are known to be $\mathrm{Cu}, \mathrm{Mg}, \mathrm{Si}$ and $\mathrm{Fe}$. All the four elements introduce the peak at almost the same temperature, but Si has the most dominant effect. The addition of Ge, belonging to the same group in the periodic table, introduces a small peak at a temperature slightly higher than that of the Si-added specimen. Since Si has the predominant effect, a detailed investigation was made on $\mathrm{Al}-\mathrm{Si}$ alloys.

Figure 3 shows the result for a series of specimens with various Si concentrations. The peak is in fact higher for specimens with higher concentration of Si. Figure 4 shows the result of successive measurements on an Al-0.93 at.\%Si. After the first heating run measurement on an as-drawn specimen up to $370 \mathrm{~K}$, the specimen was cooled down and subjected to the second run up to $450 \mathrm{~K}$. The peak shifts toward higher temperatures and gradually decreases its height on annealing. After annealing for $1 \mathrm{~h}$ at 650 $\mathrm{K}$, the peak completely disappeared. The annealing behavior of the peak in pure aluminum specimens was not very much different from that described here.

The height of the peak is strongly dependent on the mode of deformation. The peak is virtually absent or very small after torsional deformation. Severe deformation at high stress levels as in the case of cold-drawing seems to be effective in introducing the present peak. This trend has also been recognized for the peak in $\mathrm{Cu}-\mathrm{Al}$ alloys $[3,4]$.

Detailed analyses of the peak have been made for a specimen containing 0.05 at.\% Si. Figure 5 shows the internal friction peak after subtracting the background and the vibrational frequency as a function of temperature. The relaxation parameters, the activation energy $E_{\mathrm{s}}$ and the pre-exponential factor $\tau_{0}$ have been determined by the peak shift method: $E_{\mathrm{s}}=1.63 \pm 0.12 \mathrm{eV}, \tau_{0}=10^{-39.5 \pm 0.3} \mathrm{~s}$. The dashed line is the Debye peak of single relaxation calculated with the above relaxation parameters; the experimental curve is much broader than the theoretical one.

In the case of the Debye peak, the height of the internal friction peak, $Q_{\mathrm{m}}^{-1}$, and the associated $\Delta M$ effect, $\Delta M / M(=2 \Delta f / f: f$ the vibrational frequency) is related by

$$
2 Q_{\mathrm{m}}^{-1}=\alpha \frac{\Delta M}{M}
$$

where $\alpha$ is unity for a single relaxation process. For the present peak shown in Fig.5, $\alpha$ is 0.25 . This means that the peak is broadened by the distribution in the relaxation times. If we adopt the log--normal distribution in the relaxation time [14], the value of the distribution parameter, $\beta$, is 6.75 and the relative peak width, $r(\beta)$ is 4.48 from Table 4 in Ref. [14], implying that the peak is broadened by a factor of 4.48 than that of single relaxation. The anomalously small values of $\tau_{0}$ for this type of peaks have been recognized in several previous investigations $[4,5,6,8,9]$.

\section{DISCUSSION}

Although the origin of the present peak is not yet clear, some remarks are made here to give a clue towards a better understanding of the phenomenon. The requisites for the appearance of the peak are the presence of solute atoms and severe deformation or high density of dislocations. The gradual decrease in the peak height by annealing above $450 \mathrm{~K}\left(\sim T_{\mathrm{m}} / 2\right)$ and the annihilation of the peak by annealing around $650 \mathrm{~K}$ also suggest the involvement of dislocations in this relaxation peak.

Among various solute atoms examined in this experiment, $\mathrm{Si}$ is the most effective to introduce the peak. Although the other elements such as $\mathrm{Cu}$ and $\mathrm{Mg}$ also seem to be effective to some extent, it is not at all clear. One should note the fact that nominally high pure aluminum of five nine does exhibit the peaks 
of considerable magnitudes. Thus, some elements such as $\mathrm{Si}$ or some unidentified impurities unintentionally introduced in preparation of alloys with $\mathrm{Cu}$ or $\mathrm{Mg}$ can be responsible for the peak. In some previous investigations $[8,9]$, measurements were made for specimens of just one concentration. In such experiments, it seems difficult to ascribe any observed phenomenon to the contribution of the solute atom; impurities present in the raw material, not the solute element added intentionally can be responsible for the phenomenon.

The features of the present peak are fairly different from those observed for conventional relaxation peaks of internal friction. Some of such features can be explained by considering a system of strong mutual interaction. In an earlier paper, one of the present authors discussed the relaxation process of a system in which anelastic elements exhibit strong interaction [15]. For such a system, the internal friction $Q^{-1}$ and the associated $\Delta M$ effect, $\Delta M / M$, can be written as

$$
\begin{aligned}
& Q^{-1}=\frac{T_{0}}{T-T_{\mathrm{c}}} \frac{\omega \tau^{\prime}}{1+\left(\omega \tau^{\prime}\right)^{2}} \\
& \frac{\Delta M}{M}=\frac{T_{0}}{T-T_{\mathrm{c}}} \frac{1}{1+\left(\omega \tau^{\prime}\right)^{2}},
\end{aligned}
$$

where $T_{0}$ is a constant, $T_{\mathrm{c}}$ is a critical temperature, which expresses the strength of the interaction, $\omega$ is the angular frequency and $\tau^{\prime}$ is the relaxation time, which is related to that in the absence of the interaction, $\tau$, as $\tau^{\prime}=\tau /\left(1-T_{\mathrm{c}} / T\right)$. The salient features of the relaxation of the system may be summarized as follows. (1) The interaction modifies not only the magnitude of the relaxation strength, but also the relaxation time. (2) With increasing the interaction, the peak shifts towards higher temperatures. (3) When $T_{\mathrm{c}}$ approaches the peak temperature, the peak becomes higher and narrower. The apparent activation energy becomes larger and the apparent preexponential factor $\tau_{0}$ becomes smaller.

As a numerical example, we have chosen somewhat arbitrarily the following values: $\tau_{0}=10^{-13} \mathrm{~s}$, $E=0.46 \mathrm{eV}$, and have drawn the curves of $Q^{-1}$ for various values of $T_{\mathrm{c}}$ as shown in Fig.6. The apparent activation energy, defined by $E_{\text {app }}=\mathrm{d} \ln \tau^{\prime} / \mathrm{d}(1 / T)$, is $0.79 \mathrm{eV}$ and the apparent preexponential factor is $2.02 \times 10^{-20} \mathrm{~s}$ for $T_{\mathrm{c}}=200 \mathrm{~K}$. Although it is still far from quantitative agreement, the trend is in the right direction. Detailed analysis of the peak will be reported in a separate paper.

In conclusion, the anomalous feature of the peak observed in dilute aluminum alloys in the heavily cold worked state can be explained qualitatively as the relaxation of a strongly interacting system.

\section{REFERENCES}

[1] Nowick A.S. and Berry B.S., Anelastic Relaxation in Crystalline Solids (Academic Press, New York and London, 1972) pp.401-410.

[2] Iwasaki K., Koiwa M. and Hasiguti R.R., J. Phys. Soc. Japan 39(1975) 117-124.

[3] Iwasaki K., Lücke K. and Sokolowski G., Acta metall. mater. 28(1980) 855-868.

[4] Koiwa M., Onozuka T. and Hirabayashi M., Phil. Mag. 32(1975) 441-455.

[5] Iseki M., Koiwa M. and Hirabayashi M., Proc. 6th Int. Conf. Internal Friction and Ultrasonic Attenuation in Solids, R.R. Hasiguti and N. Mikoshiba, Eds. (Univ. Tokyo Press, Tokyo, 1977) pp.659-663.

[6] Kong Q.P., Lücke K. and Sokolowski G., J. de Physique, Colloque C5(1981) 271-277.

[7] Iwasaki K., J. Phys. Soc. Japan, 49 (1980) 271-278.

[8] Zhang J.X., Kê T.S., Li. G.Y., Fantozzi G., Gobin P.F., and Weller M., phys. stat. sol (a) 70(1982) 159-165.

[9] Kong Q.H., Li G.Y. and Kê T.S., J. de Physique, Colloque C5(1981) 265-270.

[10] Pan Z.L., Wang Z.G., Kong Q.H. and Kê T.S., Materials Sci. and Eng. 49(1981) 101-107.

[11] Fang Q.F. and Kê T.S., Acta metall. mater. 38(1990) 419-424.

[12] Guan X.S., Numakura H. and Koiwa M., to be published.

[13] Numakura H., Miura M., Matsumoto H. and Koiwa M., ISIJ International 36(1996) 290-299.

[14] Nowick A.S. and Berry B.S., IBM Journal, Res. Develop., 5 (1961) 297-320.

[15] Koiwa M., Proc. 6th Int. Conf. Internal Friction and Ultrasonic Attenuation in Solids, R.R. Hasiguti and N. Mikoshiba, Eds. (Univ. Tokyo Press, Tokyo, 1977) pp.665-669. 


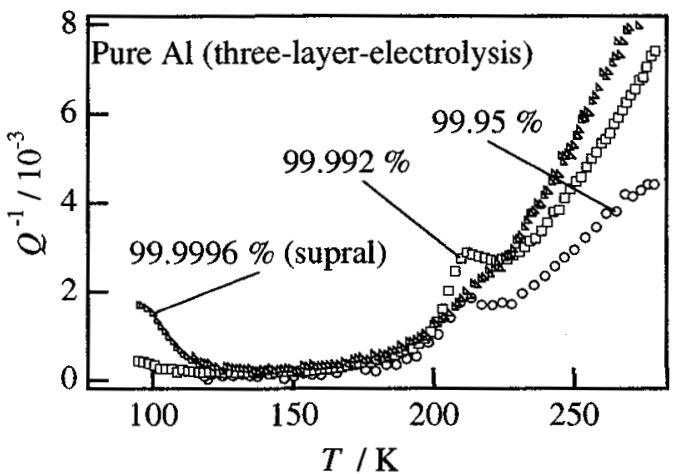

Figure 1: Internal friction of cold-drawn "pure" aluminum specimens of three different purities supplied by Sumitomo Chemicals Ltd.

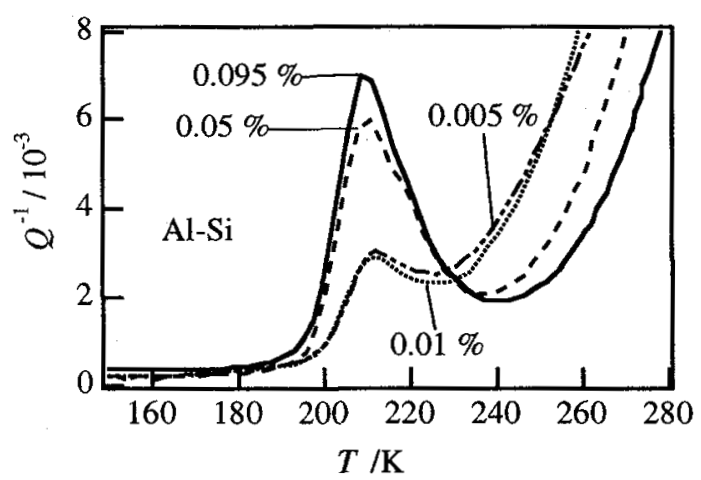

Figure 3: Effect of Si concentration on the peak height.

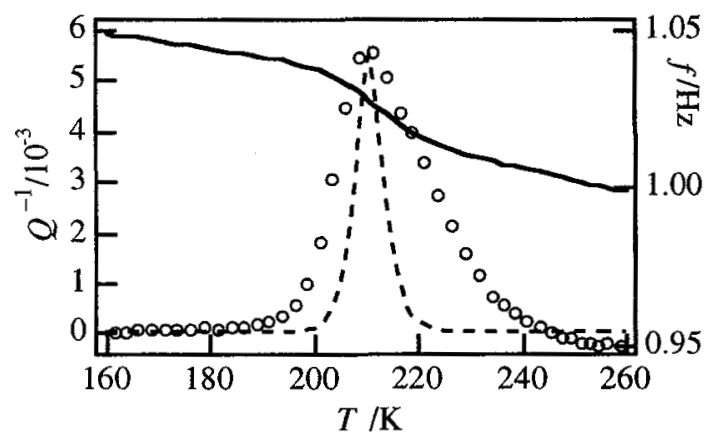

Figure 5: Internal friction after subtraction of background (open circles), and the vibration frequency for $\mathrm{Al}-0.05$ at $\% \mathrm{Si}$ specimen. The broken line is the single relaxation Debye peak calculated with $E=1.63 \mathrm{eV}$ and $\tau_{0}=1.62 \times 10^{-40} \mathrm{~s}$, which were determined by the peak shift method.

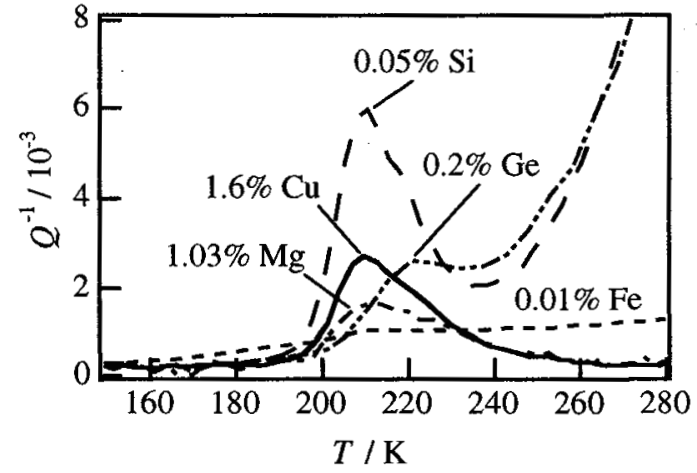

Figure 2: Internal friction of as-drawn aluminum alloy specimens.

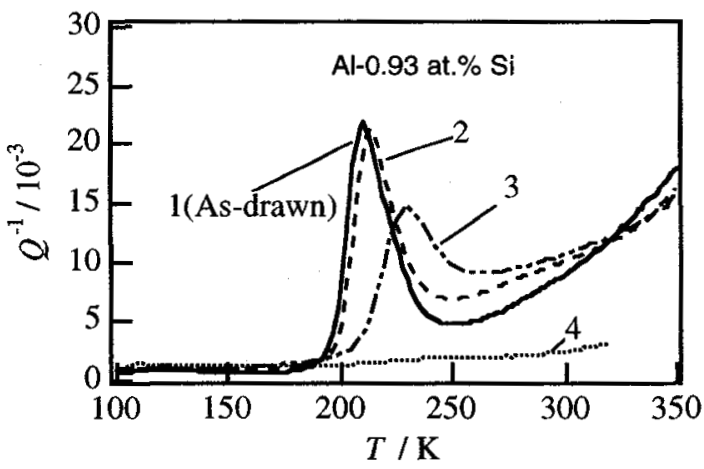

Figure 4: Effect of annealing. A series of measurements were made up to successively higher temperatures: curve 1: $370 \mathrm{~K}, 2: 450 \mathrm{~K}, 3: 650 \mathrm{~K}, 4: 320 \mathrm{~K}$. See text.

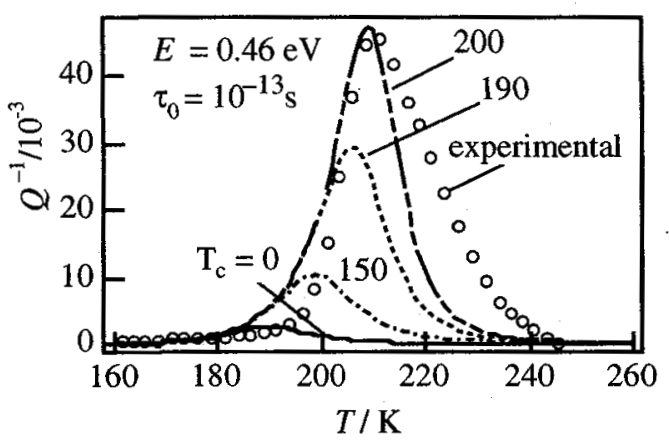

Figure 6: Internal friction curves with several values of Tc for the case of strong interaction between anelastic elements. The open circles are the experimental data of the $\mathrm{Al}-0.05$ at\% $\mathrm{Si}$ specimen. 